\title{
EL CAMINO DÉLFICO: TRANSFORMACIÓN Y PLENITUD DEL FUTURO EN LA ESCRITURA DE LAS ELEGIES DE BIERVILLE DE CARLES RIBA
}

\section{THE DELPHIC PATH: TRANSFORMATION AND FULFILMENT OF THE FUTURE IN ELEGIES DE BIERVILLE BY CARLES RIBA}

\author{
Marta LÓPEZ VILAR \\ Universidad Autónoma de Madrid \\ marta.lopez.vilar@gmail.com
}

Resumen: En este artículo expondré cómo la tragedia del exilio republicano español de 1939, marcado inexorablemente por la desposesión y la pérdida del origen, inicia una búsqueda de la plenitud y la esperanza en el poemario Elegies de Bierville de Carles Riba. Para ello, me centraré en el estudio de la elegía VIII, en la que Delfos responde a esa idea de transformación. El lugar délfico como epicentro del conocimiento del hombre es el motor que metamorfosea la hendidura del exilio hacia la escritura como un presagio, un futuro que mantiene la palabra en la eternidad, siendo inalcanzable pero, a su vez, acto de escritura. Para Carles Riba, éste será el sentido de la salvación y restauración en la poesía.

Palabras clave: Carles Riba; poesía catalana del siglo XX; exilio; plenitud; Elegies de Bierville; Delfos; escritura.

Abstract: In this article, I will discuss how the tragedy of the 1939 Spanish Republican exile, inexorably marked by dispossession and the loss of origin, initiates a pursuit for wholeness and hope in Carles Riba's poetry book, Elegies de Bierville. In doing so, I will focus on Elegy VIII, in which Delphi responds to the notion of this transformation. The Delphic place as the epicenter of human knowledge is the impetus that transforms the rupture of exile into writing as an auspice, a future that holds the word in eternity, unattainable but, in turn, act of writing. For Carles Riba, this will be the sense of salvation and restoration in poetry.

Keywords: Carles Riba; Catalan poetry of XX century; exile; fulfilment; Elegies de Bierville; Delphi; writing. 
$\mathrm{P}$ arece contradictorio que dentro del ámbito oscuro del exilio pueda hablarse de plenitud, de esperanza en ese lugar indefinido que es el futuro. Hablar del exilio es sugerir una herida, no sin motivos. Sin embargo, si atendemos a la lectura de las Elegies de Bierville ${ }^{l}$ puede verse que, desde esa desgarradura original, esa escisión abisal que provoca la pérdida del origen, de la lengua, del espacio, es el inicio hacia la búsqueda de ese mismo origen. Todo en el libro de Riba es una pulsión hacia la raíz. Explicaba Riba en su "Prefacio a la segunda edición":

En la íntima realidad, me enfrentaba a mí mismo, lleno de mí mismo y no finito y del que de mí mismo hubiera dado; me enfrentaba a mí mismo, recogido en mis propias fuerzas, por tal de que por ellas me conociera y me acabara y me expandiera hacia el encuentro de una idea divina. Eso era volver, sí «hacia mi alma como a una patria antigua»; la frase del gran romántico alemán se me repetía hasta la obsesión (Riba, 2011: 19-21).

Ese regreso que es búsqueda hacia la plenitud de sí mismo, comienza ya en la primera elegía: «Era secreto el camino, fabuloso de tristezas divinas, / hasta que las aguas vivientes me recordaron un nombre, / ¡oh inefable! y una callada manera sencilla /de sosegar el pensamiento por una gracia tenaz» (Riba, 2011: 33).

Sin embargo, dada la amplitud del tema, me centraré exclusivamente en cómo Riba articula un camino hacia la plenitud desde la desgarradura del exilio, concretamente, en la reconstrucción de la idea délfica del futuro - el presagio - . Este concepto se plasma con claridad en la elegía VIII donde el poeta recupera la imagen del Delfos encontrado en 1927, durante un viaje junto a su esposa, la poeta Clementina Arderiu. Riba se consideraba un escritor que

[...] de professió i de vocació no pot prescindir de Grècia. Feia aleshores dotze anys que jo havia fet l'inoblidable viatge a Grècia, a reconèixer els paisatges de tants autors estimats $i$ traduïts per mi, $i$ des d'Atenes vaig, vam anar a Súnion. Ja s'ha dit que anar a Grècia, a Itàlia, a un país al qual un s'ha preparat, al qual un deu alguna cosa de la seva construcció, és anar a omplir uns noms, omplir amb visions uns noms, uns noms que ens empenyen a trobar el lloc que hi correspon. La dèria — no puc dir altre mot perquè és el just- de veure Súnion em venia d'un vers bastant dolent però extraordinariament suggestiu de Moréas: «Sunion, Sunion, sublime promontoire» (Riba, 1984: 32).

Este recorrido hacia los orígenes de mundo poético ribiano, Grecia, se plasmaría inevitablemente en las Elegies de Bierville. Pero centrémonos en la mencionada elegía VIII.

\footnotetext{
${ }^{1}$ El proceso de publicación de las Elegies de Bierville de Carles Riba fue convulso. La primera edición, clandestina, se publicó en Barcelona en 1943, con un falso pie editorial de Buenos Aires con la fecha de 1942. La segunda edición se publicó en Santiago de Chile, en 1949, en la editorial "El Pi de les tres branques" (fundada en 1947 por Xavier Benguerel y Joan Oliver - Pere Quart-). La tercera edición, esta vez legal, en Barcelona en 1951 en la editorial Óssa Menor. Finalmente, la cuarta edición fue publicada como homenaje que numerosos intelectuales le hicieron a Riba en "Ínsula", en 1956. Bajo el título Obra poética. Antología, se incluyeron diversos textos poéticos de Riba y la traducción completa de las Elegies realizada por Alfonso Costafreda. Para este trabajo, yo citaré la edición bilingüe castellana de las Elegies de Bierville que yo misma realicé en 2011 en la editorial Libros del Aire, en Madrid.
} 
El camino délfico: transformación y plenitud del futuro en la escritura de las Elegies...

\section{Transformación y presagio délficos}

Pocos lugares en el mundo pueden ofrecer, simplemente con su visión, el verdadero encantamiento misterioso de la naturaleza como es Delfos. Cuando empieza a vislumbrarse a lo lejos, llegando desde el camino ateniense y habiendo dejado atrás la bella ciudad de Arájova ${ }^{2}$, cierta extrañeza comienza a apoderarse del viajero. Extrañeza que, sin embargo, contiene en sí misma un placer que nos aparta de la realidad del viaje que se emprendió. Comienza a mirarse de otra forma. La naturaleza se muestra ante nosotros como una aparición hechizante. Se da en nosotros el verdadero $\theta \alpha \tilde{v} \mu \alpha^{3}$ de aquello que nace de lo natural, brillando, para absorber lo que de humano hay en nosotros.

El hombre deja a un lado su condición de tal para convertirse o dejarse llevar hacia un lugar invisible. En Delfos permanece ese poder que nos arrastra de la misma manera que Perséfone fue arrastrada por ese milagro de la naturaleza en forma de narciso. Su fascinación le costó condenarse intermitentemente a los infiernos.

Delfos es el lugar sagrado del conocimiento. Pocas diferencias hubo en la Grecia clásica entre lugar y sacralidad. En la tradición griega era inevitable asociar a los territorios la noción sagrada. Como apuntan Mauss y Hubert, todo aquello que pudiera denominar al grupo, a lo social, formaba parte de la parcela de lo sagrado (Schwarz, 2008: 46). La expansión del individuo, lo único, era una pieza determinante de su verdadero lugar en lo social. De ahí, la elevación sagrada de Odiseo, por ejemplo, hacia Ítaca, su patria. Para Riba, su espiritualidad es su patria.

Experimentar míticamente es una manera más de conocerse a sí mismo para el hombre contemporáneo. La sabiduría del mito, que en su tiempo no se denominaba así, sino origen o causa de las cosas, se ha heredado en el pensamiento poético de la Edad Contemporánea. Cuando Pausanias describe Delfos en el libro X se refiere a la máxima délfica de la aproximación del hombre a su centro:

En el pronao de Delfos están escritas máximas útiles para la vida de los hombres. Han sido escritas por hombres que los griegos dicen que fueron sabios. [...] Pues bien, cuando llegaron a Delfos, estos hombres ofrendaron a Apolo las celebradas máximas «Conócete a ti mismo» y el «Nada en exceso» (Pausanias, 1994: 416-417).

El autoconocimiento se convierte en fundamento y base de su manera de estar en el mundo. Es la máxima sabiduría que todo hombre puede hallar a lo largo de su corta existencia. ¿Qué nos dice, en el fondo, esta premisa? Que el hombre, a su vez, vive en un perpetuo exilio de sí mismo. Su tragedia nace de ahí, de esa profunda escisión de su propio ser, ciego. El hombre parece destinado a la misma profecía que el oráculo délfico dio a Homero: «Dichoso e infortunado, pues naciste para ambas cosas, buscas una patria. Tienes una tierra natal, pero no una patria» (Pausanias, 1994: 417).

El hombre nace, pero no tiene el lugar sagrado de la patria que es su propio conocimiento. El saber de sí es su propio centro, de la misma manera que Delfos fue el centro del mundo. La noción de ese centro posee ciertas connotaciones sagradas que implican aquello que está en un lugar sin

\footnotetext{
${ }^{2}$ Según el mito, ciudad de origen de Aracne.

${ }^{3}$ Etimológicamente, concibo el término "thauma" como aquello que asombra, maravilla. La etimología la he consultado en el Dictionnaire étymologique de la langue grecque. Histoire des mots, de Pierre Chantraine.
} 
pertenecer a nada. El centro no se inclina hacia ningún punto cardinal. El centro es la coordenada del aislamiento. Insertar la sacralidad en un lugar profano perpetuaba el acto de centralizar un nuevo nacimiento del mundo, el origen del que todo hombre sentía nostalgia por encontrar ahí, en ese lugar inaccesible, su verdadera patria. Así lo expresa muy bien Mircea Eliade:

[...] todo lugar sagrado, todo lugar que manifestaba una inserción de lo sagrado en el espacio profano, se consideraba también como un «centro». Estos espacios sagrados también podían construirse. Pero su construcción era en cierto modo una cosmogonía, una creación del mundo; lo cual no puede ser más natural, puesto que, como hemos visto, el mundo fue creado a partir de un embrión, de un «centro» (Eliade, 1986: 54-55).

De la misma manera que el hombre necesita ese centro para localizar su origen, asimismo vive ese mismo hombre un nuevo nacimiento de sí. Alcanza por unos instantes el mismo rehacerse de Dionisos. Esta es la experiencia, aproximada, de la llegada a Delfos y de todas las connotaciones que para el hombre ha tenido. Riba así lo aprecia en esta elegía. El poeta catalán recuerda ese punto central desde la desubicación del exilio. En parte, esa era la naturaleza del centro que no pertenece a ninguna coordenada. Tan solo desde la evocación puede atraer hacia sí mismo la aparición brillante del centro. Así lo expresa Riba en su Presentació de les Elegies de Bierville:

Sempre de lluny, d'una manera fantasmal, se'm representa aquest paisatge vist anys enrera i dialogo amb la companya de tota la meva vida - va ser companya meva del viatge a Grècia, companya meva també en poesia (Medina, 1994: 131).

Todo en Riba aparece de manera fantasmal, inaprensible, pero transfigurado en experiencia invisible y sensitiva. Riba, sin embargo, desde esa invisibilidad de una existencia pasada que tanto recuerda a El Archipiélago de Hölderlin ${ }^{4}$, siente el poder del futuro en todo aquello que lo rodea. Todo en Delfos es futuro, presagio, un adelantarse al acontecimiento que devela la propia esencia del hombre. Quien no tiene presente - Riba sintió que su tiempo se abolía gracias a la desposesión cruel del exilio- y su pasado se conforma de apariciones de todo lo perdido, solo puede anhelar lo más indefinido y ex-céntrico: el futuro. Así lo expresa Riba en la Presentació: «És no solament tota la suggestió del lloc, de les profecies del lloc nacional, de la recerca del que pot ser el futur» (Medina, 1994: 131).

El futuro es el tiempo indefinido donde radicará la nueva visión de la religiosidad en la Edad Contemporánea. La eterna espera espiritual apenas aspira a lo ininteligible de un tiempo por venir, como ya apuntaron gran parte de las poéticas contemporáneas ${ }^{5}$, alejadas, eso sí, de discursos utópicos. Solo en el futuro se halla lo trascendente, de ahí la vigencia del presagio. La Palabra poética se halla

\footnotetext{
4 «mudo está el dios délfico, y solitarios y abandonados se encuentran / desde hace mucho tiempo los senderos por donde antes, / dulcemente conducido por las esperanzas, subía el hombre / preguntando hacia la ciudad del veraz profeta. / Mas desde lo alto la luz habla todavía hoy a los hombres, / llena de hermosos significados» (Hölderlin, 1985: 79).

${ }^{5}$ Martin Heidegger, por ejemplo, en su conferencia sobre el poema de Hölderlin, Andenken, asienta las bases de esa poesía enraizada en la imagen del "dios por venir" que alcanzaría el pensamiento poético contemporáneo. La escritura, de esta forma, está construida sobre una fractura de la nueva sociedad. Es interesante el libro de Jacques Derrida: El siglo y el perdón (entrevista con Michel Wievorka): seguido de fe y saber.
} 
en la esperanza ${ }^{6}$ - en esa prolongación que da la esperanza - de un futuro reintegrador que se concibe en el adentro humano ${ }^{7}$. Se asimila a la salvación cristiana de la que Riba se encargó de dotar a su ejercicio poético.

El futuro es lo secreto, el contenido misterioso que da al hombre el valor de saberse presente en algo que no existe y que nunca existirá, porque esa es la intrínseca capacidad anuladora de ese mismo futuro anhelado. El poeta, al fin y al cabo, busca penetrar en la insondabilidad de nuestra propia eternidad, también de la suya propia. Esa eternidad mantiene la impermeabilidad a la muerte que el hombre necesita. El futuro seguirá existiendo aunque el hombre ya no esté para esperarlo. Ese consuelo articula la capacidad esperanzadora de la existencia. Aquello que siempre acaba está sometido a su eterna herida de existir: la tragedia del hombre en el más puro estilo nietzscheano ${ }^{8}$. El hombre, en su ilusión de futuro y su conciencia de que algo de él pervive a través de la naturaleza gracias al futuro, construye su estancia existencial alrededor de ese marco inexistente del tiempo por venir. Por ello la Palabra siempre precederá al poeta, irá siempre delante de él y mantendrá siempre la misma inalcanzabilidad que la hace deseada. La intrahistoria se sustenta, de este modo, en la prolongación de un vacío.

El poeta se constituye como aquello que indaga en la especialidad infinita de su existencia confiada a un futuro apocalíptico, de revelación. Pero también se asemeja a la figura que anuncia. Según el Evangelio, la palabra vida posee el significado de vida eterna (Schajowicz, 1962: 27). El arte libera de esa angustia de la finitud cruel que acecha al hombre, aunque no deja de ser una mera ilusión por la incapacidad natural de ser presente. La escritura poética se desvela como el acto de herida en el tiempo. Herida que es instante a su vez. La escritura abre un trazo profundo en el que vierte un anuncio de algo que el poeta — ni nadie - podrá experimentar. El poeta consigue alejarse de la historia para convertirse en el verdadero derrocador de la linealidad de lo histórico. Sin límites se aproxima a la sacralidad necesaria, abre el abismo de sí mismo para absorber como un agujero negro todo aquello que en su diafanidad se ha mostrado imposible. Ser en lo Abierto de Rilke, ese es el objetivo de un poeta como Riba. Por eso regresa a Delfos, el lugar del futuro en un centro sin lugar. Por eso el presagio y la creación fueron ramas de un mismo árbol. Lo aislado es la verdadera manera de ser Uno, lo puro: lo Absoluto. Así lo explicó Plutarco, que muy bien conocía el oráculo délfico: «De modo que ser uno y sin mezcla es siempre propio de lo incorruptible y lo puro» (Plutarco, 2007: 200).

La capacidad anuladora del tiempo, de herirlo y mostrarnos la experiencia numinosa de ser es una manera de anunciar la capacidad del conocimiento del hombre. Desde lo atópico se remite a un punto de la historia. Así se articula el sufrimiento del hombre que, como muy bien indica el profesor

\footnotetext{
${ }^{6}$ Recordemos el fragmento final de la carta escrita por Riba a Pierre Rouquette (30-5-1940): «Ens salvarem, tinguem-ne la fe: aquella fe que, com deia Péguy, més plau a Déu, i que és com una esperança» (Riba, 1991: 134).

${ }^{7}$ Algo que se verá claramente en la elegía IX.

8 «Es un fenómeno eterno: mediante una ilusión extendida sobre las cosas la ávida voluntad encuentra siempre un medio de retener a sus criaturas en la vida y de forzarlas a seguir viviendo. A éste lo encadena el placer socrático del conocer y la ilusión de poder curar con él la herida trágica del existir, que se agita ante sus ojos, al de más allá, el consuelo metafísico de que, bajo el torbellino de fenómenos, continúa fluyendo indestructible la vida eterna» (Nietzsche, 2004: 154).
} 
Jaume Medina, comienza a tejer un entramado de correspondencias entre su existencia y el mito ${ }^{9}$. El mito, como apunta Schajowicz, ejerce en el hombre la función de catarsis que lo lleva a poder experimentar cierta restitución en su mirada (Schajowicz, 1962: 23). La realidad se purifica ante su nuevo nacimiento indemne, gracias a la palabra. Solo así florece la esencia de las cosas y espiritualiza aquello que rodea al hombre. Lo mítico es lo que favorece ese futuro al que nos hemos referido más arriba. Dice Schajowicz: «El mythos no expresa meramente lo "visto", es decir, el testimonio de una teofanía pasada, sino que nos invita a la entrevisión hic et hunc de lo divino o, por lo menos, a la intuición de sus vestigios en un mundo desdivinizado» (Schajowicz, 1962: 24).

Esos vestigios nos dan la razón cuando decimos que solo el futuro es lo que permite concebir una forma de existencia sagrada. El poema queda como estigma de esa búsqueda del futuro. Y en ese poema se ha transformado algo, se ha creado un hueco abismal, por el que caerá la realidad sensible. A eso se refiere Riba con sus Fábulas ${ }^{10}$, que, desde luego, se mantienen lejos de meras invenciones provenientes del pasado:

Sea o no a nuestra medida lo que nos pase, se parezca
a nosotros o no, mujer, en nosotros el grito
de sufrimiento o de gloria querrá hablar - - oh! no importa,
tan solo a nosotros o también a los otros--
hablará dulcemente, articulado por la sabiduría de los siglos
y de las Fábulas, de las canciones maternales
y profundamente de lo que engendra vida en la secreta y precisa tierra;
eterna y tierna voz para crearnos todos,
mujer, en cada borbotón de su chorro; tu voz y la mía,
la doble voz sobre el mismo instrumento
de un destino común. Y no podría separar la muerte
lo que ha hecho un solitario canto al oído de los dioses (Riba, 2011: 53-55).

No son ficciones, sino reconstrucciones del mundo que se convierten en hipóstasis, una realidad verdadera que se da por sí misma y que se desarrolla en el futuro. Las Fábulas y las canciones maternales, originarias, son las que engendran el renacimiento de todo lo viviente. La poesía, de este modo, es el medio para re-crear el mito, que es también inspiración ${ }^{11}$. Así lo registra Riba en sus comentarios a las Elegies de Bierville: «Des dels romans, sobretot atribuit a Castàlia el do d'inspirar els poetes» (Medina, 1994: 136).

El mito délfico se ha convertido en inspiración poética. En el fondo, retomar el mito, actualizarlo y dotarlo de vigencia en el acto del poeta es una manera de atraer hacia la historia el discurso originario

\footnotetext{
${ }^{9}$ «El parlar del crit gloriós o sofrent serà articulat per la saviesa dels segles i de les Faules, això és, dels mites a través dels quals es farà una representación simbòlica de la seva vivència i del coneixement adquirit per la humanitat al llarg de la història» (Medina, 1994: 291).

${ }^{10}$ Carles Miralles también lo relaciona con los lazos del humanismo europeo: «La llengua, la poesia i la terra, junt amb la tradició de l'humanisme europeu ("la saviesa dels segles/ de les Faules", v. 27-28), constitueixen un tresor irrenunciable i són, una mica com a Hölderlin, distintes maneres de dir una única cosa, igual com tenen -i això és el que explica l'elegia següent- una expressió política que Riba remunta a la creació de la democràcia» (Miralles, 2007: 278). Por otro lado, mantengo la mayúscula para respetar la ortografía del autor.

${ }^{11}$ «Creer en la inspiración implica reconocer tácitamente la presencia de dioses a quienes el poeta se siente ligado en virtud de la verdad que ellos encarnan, verdad que desea manifestarse como palabra. Quien dice inspiración dice mythos. Un poema suele ser el resultado de una iniciativa de transfigurar la realidad, o sea, la respuesta creadora del hombre a una solicitación divina» (Schajowicz, 1962: 25).
} 
del mundo. El principio de la cultura, del hombre, fue un mito y regresar a él es una manera de saberse perteneciente a una patria que fue lentamente abandonada. ¿Acaso no se percataron de ello Hölderlin, Wordsworth o Mallarmé?

La Fábula va unida a la canción maternal. El canto aparece a lo largo de las Elegies de Bierville, pero no es casual que, precisamente en la elegía délfica por antonomasia, vuelva a aparecer. Georges Roux, a quien tanto debemos por sus estudios sobre los oráculos délficos, apunta que las musas délficas se llamaban, simbólicamente, como cada una de las cuerdas de la lira. Según los peripatéticos, ellas son las que rigen las fluctuaciones de la tierra y del sol de donde nace el pneuma de la inspiración (Roux, 1976: 188). Pero también hay estudios que apuntan a que Apolo se ausentaba, durante los meses de invierno, de Delfos — no había oráculos- y el canto del peán apolíneo era sustituido por el ditirambo dionisíaco (Flacelière, 1993: 42). La armonía telúrica de Delfos es capaz de alterar el devenir del tiempo, abolir la muerte. Escribe Riba en esta elegía: «Y no podría separar la muerte / lo que ha hecho un solitario canto al oído de los dioses» (Riba, 2011: 55).

Hay algo que es más potente que el poder destructor de la muerte: el canto divino que emerge de la naturaleza y que es lo que se mantiene intacto más allá de todo lo finito.

Todo en Delfos remite a lo armónico. En el texto de Plutarco «Sobre la misteriosa E que hay en Delfos» el autor describe la relación que existe entre la E, el número cinco, el fuego y su consideración divina (Plutarco, 2007: 187). Armónicamente se estructura el universo que se proyecta en el centro que es Delfos.

Hemos mencionado uno de los elementos primordiales que conduce la lectura de esta elegía: el fuego. El mismo Plutarco recuerda a Heráclito en el mismo texto al que nos hemos referido anteriormente $^{12}$. Del mismo modo, Riba presenta numerosas evocaciones sobre el fuego. Escribe en esta elegía: «Són abruptas con nombres casi de mujer amorosa, / Nombres para ser presente tan solo dentro del fuego: / la Llameante y la Rosada, antorcha más pura de la mañana» (Riba, 2011: 53).

El tono visual que recorre esta elegía es el del color del fuego que dota al paisaje de cierto poder extático $^{13}$. Los nombres de las rocas Fedríades mantienen una estrecha relación con el fuego, elemento íntimamente ligado a la poesía. La Llameante y la Rosada son llamadas las Brillantes (Fedríades). El mismo apelativo, brillante, era el que designaba a Apolo. Estas rocas alcanzan una grandiosidad incomparable que incitan a alzar la vista hasta la inmensidad de las alturas. Seferis escribe en su artículo "Delfos":

Cuando se recorre el camino que sube el Parnaso por el lado del estadio te encuentras frente a esa enorme herida abierta que, como por un hachazo de Hefesto, separa de arriba abajo las dos Fedríades hasta la fuente Castalia y más abajo aún, hasta el fondo de la cañada Plistós. Se puede sentir el temor de una vida herida que lucha por respirar mientras todavía pueda, en la luz, y que se alegra con el alba y con la salida del Sol (Seferis, 1999: 39).

\footnotetext{
12 «el fuego se convierte en todas las cosas, / y éstas a su vez en fuego, / el oro se convierte en moneda, / y la moneda se convierte en oro, como dice Heráclito» (Plutarco, 2007: 184).

13 “«El verdadero significado del «calor mágico» y del «dominio del fuego» no es difícil de adivinar: esos "poderes maravillosos" indican el acceso a un cierto estado extático o, sobre otros planos culturales (en la India, por ejemplo), a un estado no condicionado, de perfecta libertad espiritual» (Eliade, 1991: 97).
} 
La altura y el fuego son dos de los conceptos que rodean la descripción de este lugar sagrado. El camino délfico al que hace referencia Riba, fue cultivado por Hefesto, dios del fuego. Así lo explica Esquilo en Las Euménides:

Él [Apolo] dejó el lago y la roca de Delos y, tras arribar a las costas de Palas, frecuentadas por los navegantes, llegó a este país y a su sede monte Parnaso. Lo acompañaron con solemne veneración las hijas de Hefesto, que construyeron el camino y cultivaron una tierra hasta entonces inculta (Esquilo, 1986: 497).

El paisaje ígneo se reconstruye desde el interior del poeta que pide abolir la vista para sentir la nueva presencia recobrada del lugar perdido. Escribe Riba en esta elegía: «Cierra los ojos en el murmullo: estamos en el délfico camino. /¿Reconoces las Rocas, las presencias absolutas, / cómo nos inundaron verticalmente los ojos hasta el azul; / elevadas de un vuelo más alto (¿vuelves a verlo, Amor?) que unía / sus dos leoninas frentes como un mismo pensamiento?» (Riba, 2011: 53).

El azul, la altura, el cielo que también aparece en la elegía XI, es el camino direccional que toma esta elegía. Altura que también es profundidad hacia el alma al pedir ese cerrar de ojos que evoca y mira hacia esa herida a la que Seferis hace referencia. El paisaje de Delfos es una herida, es cierto. Y basta visitarlo una sola vez y darse cuenta de que todo en él es herida del tiempo, de la misma manera que las esculturas que en él se encuentran también son víctimas de esa desposesión del tiempo, pero también de esa ausencia de muerte. Algo permanece en los ojos del Auriga délfico, con su mirada fija y oscura mirando hacia el blanco de la pared de un museo. Delfos es un lugar indemne, herido pero indemne, en su esencia de sacralidad. Por ello Riba regresa a él. El poeta es capaz de profetizar, como bien sabía el gran poeta griego Ánguelos Sikelianós ${ }^{14}$ y qué mejor que Delfos para enclavar la voz poética. Tanto para el poeta griego como para Riba, la Naturaleza es el ente cosmogónico donde se enraíza el centro, el comienzo primordial ${ }^{15}$. No olvidemos que, originariamente, las primeras profecías délficas pertenecían a la Tierra. Aún quedan muchos vestigios de ese oráculo ctónico que recuerda el verdadero significado matricial del lugar, eterno generador de vida ${ }^{16}$. Por eso la Naturaleza sobrecogedora de Delfos guía los aspectos más sensitivos del poeta hacia lo sagrado. De ella nace el origen. Pero esa misma Naturaleza se siente encendida, llameante, como el águila que sobrevuela esta elegía: «¿Era el águila ardiente de los reales presagios, que hace inútiles, / Pitia, el divino anuncio y la consulta en lo oscuro, / perdiéndose en tu voz?» (Riba, 2011: 53).

El águila que arde contiene el presagio de la poesía y lo divino, aquello que se adelanta y nunca es atrapado por la muerte. El águila es el animal délfico por antonomasia. Así lo reconoce su mito que recoge cómo ellas marcaron el centro del mundo al juntarse en ese lugar sagrado. Pero Riba explica detalladamente qué función ejerce este símbolo, junto con el de la Pitia, en la elegía: «L’àguila, presagi pels reis. La Pítia — aquí hi ha un eco, era necessari, de Valéry—, la Pítia en la qual sembla que s’esgarriés, o semblava que s'esgarriés, l'anunci diví» (Medina, 1994: 132).

\footnotetext{
${ }^{14}$ Hacemos referencia, especialmente, a su libro $\triangle \varepsilon \lambda \varphi \imath \kappa o ́ \varsigma \lambda o ́ \gamma o \varsigma$ Delficós logos-, de 1927.

${ }^{15}$ Según los pensadores jonios.

${ }^{16}$ Cfr. Tratado de antropología de lo sagrado, vol. III, Madrid, Trotta, 1997, p. 246.
} 
La Pitia a la que se dirige esta parte de la elegía es el vestigio de ese lugar indemne, la que vuelve eco de presagio la palabra poética. De nuevo llega el mensaje de manera dif(h)erida. El lenguaje sacralizado de la Pitia ${ }^{17}$ — vestigio de la serpiente Pitón que antes de la llegada de Apolo moraba en Delfos - se convierte en la presencia transparente que fluye por la voz. La voz espiritualizada —alta y profunda a la vez- de la Pitia se asemeja a la escritura profética del poeta que aventura el encuentro con la gracia divina.

Por otro lado, no resulta extraño que el águila en la imaginería simbólica siempre haya estado relacionado con la altura, el sol y el principio espiritual; con la luz, al fin y al cabo (Cirlot, 2011: 71). La unión de las águilas para indicar el centro con sus leoninas frentes ${ }^{18}$ profundiza en su relación con Febo, el Iluminado que es Apolo ${ }^{19}$. Desde la altura, donde se dirige la mirada, se mira hacia el abismo del ser. Lo alto es lo profundo insondable, que se encuentra más allá de la acción (Valéry, 2010: 34). Solo allí el poeta encontrará la Gracia, que favorece el conocimiento. Así lo expresa Riba: «una Gracia tenaz y discreta se nos ofrece /contra la inquietud de no saber; es necesario acercarse a ella solamente» (Riba, 2011: 53).

Conocer(se) es salvarse en la esperanza de un futuro. Ese es el valor del presagio. Al menos así lo explica Riba, de nuevo, en su Presentació de las Elegies de Bierville:

No pot evitar un que, des del punt de vista cristià, es pregunti: què vol dir això, vol dir alguna cosa, encara, aquest paisatge, les evocacions d'aquest paisatge, d'aquestes àguiles? Però és que a un cristià li importa massa saber què li pot venir del futur, si al capdavall el que li ve del futur, d'una manera contínua, perenne, a trobar-lo és la gràcia (Medina, 1994: 132).

El claro objetivo mesiánico que se condensa en el futuro muestra en realidad la necesidad de regresar al origen indemne. También es la única manera de restablecer, interiormente, la unidad del hombre en su esencia. La necesidad del futuro es la necesidad de regresar a aquello que está más allá de la muerte, a aquello que reintegra para alcanzar el estado originario y sagrado. El presagio ribiano debe entenderse desde esa necesidad reintegradora y salvadora. El poeta alcanza cierto valor visionario. A través del acto de escritura poética, de decir de otra manera ${ }^{20}$, se alcanza la salvación, como ya hemos visto que ocurre en otras elegías.

Por otro lado, la elegía continúa introduciendo, dentro del itinerario de conocimiento délfico, un ritual del agua con alto valor simbólico. Todo en Delfos está bañado por la presencia del agua. Así también lo apuntaba Pausanias:

\footnotetext{
${ }^{17}$ El recuerdo a Valéry que menciona Riba es posible que se deba al poema del poeta francés titulado «La Pitia».

${ }^{18}$ El león siempre ha mantenido correspondencias con el oro o el sol subterráneo. El águila y su condición de leonina asimila su eterna relación con el fuego y lo brillante (Cirlot, 2011: 278-279).

${ }^{19}$ Cirlot afirma que la etimología del nombre de Apolo procede de Apolion, que significa «del fondo del león» (Cirlot, 2011: 88). Pero en realidad su etimología es incierta y todos los resultados hasta el instante son viables. Platón en su Crátilo relaciona el nombre de Apolo con $\dot{\alpha} \pi \delta ́ \lambda v \sigma \iota \varsigma$ — redimir- o ḋ $\pi \delta ́ \lambda o v \sigma \iota \varsigma$ — purificación一.

${ }^{20}$ «Riba, en referir-se a la poesia que sorgirà d'aquestes aigües i que per elles puposa inmortal — “articulat per la saviesa dels segles"- parla no de «cant», sino de crit, com si aquest nou dir del poeta hagués oblidat una mica les intencions estètiques i musicals de les Estances, per a convertir-se en l'expressió de quelcom de punyent, que ha de ser sentit per la comunitat, d'aquí la força amb la qual vol ser expressat» (Boixareu, 1978: 350).
} 
Yendo de nuevo hacia el templo, después de ver la piedra está la fuente Casótide. Junto a ella hay un muro pequeño y a través del muro está la salida hacia la fuente. Dicen que el agua de esta Casótide se sumerge bajo la tierra y en el aditon del dios hace a las mujeres profetisas. Dicen que la que le ha dado el nombre a la fuente es una de las ninfas del Parnaso (Pausanias, 1994: 419).

El agua conduce el poder de profetizar, de ver el futuro, de hacer poesía, al fin y al cabo. Escribe Riba: «Mujer, tú y yo hemos bebido en el cauce glacial de Castalia / el agua dura de los dioses, pura a través del horror, / intemporal desde el fondo donde no se marcan los cambios de los signos; / la hemos mezclado con la sangre que compartimos en el amor» (Riba, 2011: 53).

El agua fluye pura a través del horror del exilio ${ }^{21}$, actuando en el poeta como un fármaco que transfigura el alma para salvarla y transfigurar lo real. El agua es intemporal, procede de ese lugar inexistente concebido para la pureza. Es subterránea, por lo tanto de origen invisible. El agua del lugar sagrado es primordial y única. Sin principio ni fin. Esta agua a la que se refiere Riba es el germen de la existencia objetiva, siempre anterior a ella. Es por el agua que germinan las cosas que no existen. A través de ese agua le fue dado al poeta el poder de nombrar en medio del silencio. La fuente Castalia fluía con el objetivo de llevar a cabo purificaciones y abluciones antes de realizar la consulta, pero también para inducir a la poesía, como ocurre en esta elegía. La propia Pitia bebía del agua de la fuente sagrada para adquirir un poder de purificación, pero también de inspiración ${ }^{22}$. En la antigua Grecia era común que todos los lugares de consulta oracular estuvieran íntimamente relacionados con el agua. En el caso más exacto del culto de la Sibila, se superpuso a otro primitivo —en la Sicilia prehistóricaque tenía como centro una gruta inundada de agua (Cfr. Eliade, 2000: 311). Los lagos o las fuentes eran considerados lugares límite entre los dioses del oráculo y los consultantes. Y todo en Delfos está rodeado o inundado por el agua. Por ello es un lugar divino, intemporal.

Pero el agua délfica está también relacionada con el poder transformador del amor. El poeta y su amada beben el agua conductora del saber, pero dice mezclarla con la sangre. Esa misma sangre es el agua del hombre, otra forma de esencia. Pero no debemos dejar de relacionar esta sangre con la misma de la que a veces bebían las profetisas para conducirlas al entusiasmo de la revelación. Más allá del sentido amoroso del agua, Riba interfiere el poder creador del agua délfica con el de la purificación de la memoria. La escritura es una forma de memoria, que recuerda a la fuente de Mnemósine de la elegía X. Escribe Riba en su Presentació: «i confesso — potser no ho havia dit mai- que després d'haver begut, amb la meva dona, l'aigua de Castàlia vam enviar uns mots al nostre gran Josep Carner dientli: "hem begut a Castàlia i us recordem"» (Medina, 1994: 132).

En esta elegía, sin embargo, también a través del agua se produce una hierofanía en lo natural. A través del agua se presenta lo divino, se entra en contacto con ello. Pero, como bien afirma Eliade, manifestarse conlleva, en cierto modo, historizarse (Eliade, 1991: 134). Ahí radica el misterio de lo

\footnotetext{
${ }^{21}$ El profesor Jaume Medina, sin embargo, atribuye ese horror al vértigo del mensaje oscuro del futuro: «L'aigua de Castàlia és, endemés, dura, pura i intemporal, adjectius convenients també a la Gràcia: és l'aigua dura dels déus, consistent i sòlida, però a través de l'horror que pot produir el conèixement del futur, intemporal des de la profunditat en la qual els canvis dels signes no reben cap marca» (Medina, 1994: 291).

22 «L'absorption de l'eau de la source sacrée devait, comme les fumigations ou la mastication de feuilles de laurier, comporter une double signification purificatrice et inspiratrice» (Amandry, 1975: 132).
} 
sagrado que se acepta de manera limitada. Lo divino circula a través del agua, se hace presente de esta forma. Pero puntualicemos que esa hierofanía, a su vez, anula la historia porque reintegra el sentido y estado original donde no existe el tiempo. Es una historización de lo divino, pero fuera de la historia. Como si apenas fuera una efímera concesión para poder hacerse palabra.

\section{Escribir el fuego. Las abejas del sol.}

La tradición oracular siempre ha mantenido una estrecha relación con el origen de la escritura. Al fin y al cabo, el presagio o la petición de conocimiento del futuro era una forma de extender el entendimiento humano y sin la escritura habría sido difícil mantenerlo.

En el oráculo de Dodona, por ejemplo, se han encontrado diversos hallazgos en forma de láminas de plomo en las que se podía leer las preguntas realizadas al dios. Están datadas del siglo VI a.C y en ellas se muestran los primeros indicios de la escritura griega (Cfr. Hernández, 2008: 33). Como se demuestra, el saber siempre se ha canalizado a través de la escritura. Ésta lo corporeiza y no debe olvidarse que la poesía es otra forma de conocimiento que también encuentra su forma a través de la escritura. Pero en el caso de esta elegía, la escritura está unida a un elemento al que ya hemos hecho referencia: el fuego. La tradición hímnica siempre ha venido acompañada de esta relación indisoluble con el fuego. Sin ir más lejos, en el "Himno a Apolo" de Calímaco, vemos que escribe: "Para ti brilla siempre el fuego inextinguible, y nunca se amontona la ceniza sobre el carbón de ayer" (Calímaco, 1980: 47).

El fuego que siempre se mantiene vivo, la llama del conocimiento apolíneo, es aquel que alumbra el oscuro y abismal camino del acto de escritura. El poeta debe conocer esa llama, saber que esa escritura es hija de un fuego alumbrador del mundo. Solo así nace el ser, desde ese fuego que penetra en el mundo. En sí, Riba está rescatando una manera de habitar la escritura de profunda raíz prometeica. Pero el poeta, al contrario de lo que ocurre en numerosas voces románticas ${ }^{23}$, no se presenta como el héroe prometeico que logra robar el fuego a los dioses, aunque posteriormente sea castigado. Poco hay, también, de la concepción prometeica unamuniana de raigambre desesperada ${ }^{24}$. El fuego ribiano es iluminador, como la esencia de Apolo. Escribe Riba en esta elegía: «[...] La floreciente imagen nos fue dulce / orgulloso corazón adentro, donde no se impone la noche / ni las alboradas blancas mienten (Riba, 2011: 53).

La noche mística que conducía al conocimiento de otras elegías - la $\mathrm{V}$, por ejemplo- se sustituye por el conocimiento luminoso del fuego que abrasa — destruye- pero también hace posible el reconocimiento del entorno de la poesía. El fuego hace nombrar los objetos, diferenciar al Otro, recorrer el sentido de la Palabra para aproximarse a ella en el mayor acto de escritura posible. El poeta

\footnotetext{
${ }^{23}$ Nos referimos a Gerard de Nerval, por ejemplo, en su poema "Le Christ aux oliviers" donde ya se atisba la muerte de Dios desde un grito angustioso de vacío. En este caso, el poeta se transfigura en Cristo para reemplazar el hueco y devolver la luz a la existencia (Vid. Nerval, 2004: 60-62).

${ }^{24}$ Pensamos, por ejemplo, en el poema "Non serviam!”: «”¡No serviré!”, gritó no bien naciera /una conciencia de sí misma, lumbre / de las tinieblas del no ser; la cumbre / de cielo tenebroso ardió en la hoguera // del conocer fatal; toda la esfera / en su seno sintió la reciedumbre / de haber sido creada, pesadumbre [...]» (Unamuno, 1999: 125).
} 
es huella sagrada, pero no desea robar esa atribución al dios cristiano de Riba, sino que se siente partícipe del paisaje iluminado. El poeta siente ser algo sagrado, pero no lo asevera. La realidad de su existencia es la que se filtra a través del canal sensitivo, no la aplastante afirmación del ser. Reconoce, como tras un Apocalipsis, todos los elementos de lo sagrado que permanecían ocultos en un conocimiento ininteligible. El poeta se convierte en algo ligero y sagrado — de clara influencia platónica como se ve en su diálogo Ion-: «iOh, cómo sentimos que éramos algo ligero y sagrado, / dueños ya de los signos que nos hallaran, Amor!» (Riba, 2011: 55).

Lo ligero y sagrado, lo volátil e inalcanzable: en eso se convierte el poeta. A la manera hesiódica ${ }^{25}$, el poeta se presenta como aquel que tiene el don de revelar un conocimiento especial que se mantiene oculto a los demás. Sí es verdad que en Hesíodo la inspiración que produce ese saber lo oculto lo provoca el pneuma o soplo de las musas, hijas de Zeus. Aquí es el fuego lo que produce esa inspiración de conocimiento. Es el fuego quien rescata al poeta de la blancura terrible de lo oculto. El poeta, eso sí, es el único conocedor de los presagios, del pasado y del futuro y de este modo protege la verdad mítica. Los signos del sentido encuentran al poeta para guiarlo, en su camino de fuego, hacía la Palabra desvelada. La escritura subterránea florece a través de la tierra gracias a la llamada inefable de la vida. Escribe Riba a continuación: «iVida querida...olivar que huyendo de las Rocas bajaba / tan inefablemente impetuoso hacia el mar! / Nada tuvimos que decirnos» (Riba, 2011: 55).

La vida anhelada nace desde esa corriente subterránea de luz y saber poético, se convierte en Naturaleza. En realidad, el hombre se enfrenta a ese callar enigmático y terrible del mundo. Iniciar una tensión primordial es marcarse con la herida del dios oculto. Vivir esa gracia solo puede darse en la exaltación de la plenitud creadora, como apuntó Valéry (Valéry, 2010: 253). Ese fluir es lo verdadero y se enfrenta a la inactividad humana, que adquiere unos ritmos alejados de lo natural. El tiempo de la poesía es el de la naturaleza que emerge como origen reintegrador. A través del agua se descubre la luz ígnea de lo poético, pero recordemos que los amantes, como las profetisas, mezclaron el agua con la sangre. Dijimos que esa sangre era el agua del cuerpo, de la presencia física del poeta, pero también la sangre es del color del fuego. La esencia iluminadora de la poesía circula por la propia existencia interior del poeta. Y así ya lo atisbaba Riba en libros como Estances ${ }^{26}$ o Del joc i del foc.

Por otro lado, el fuego siempre ha estado unido a estados de excitación de la consciencia - como los sufridos por la Pitia antes de verbalizar el oráculo-. No olvidemos que Dionisos era el otro dios de Delfos, el que se repartía la estancia en el lugar sagrado durante la ausencia de Apolo. Pero no olvidemos tampoco que también Dionisos está íntimamente relacionado con el fuego. Cuenta Nono de Panópolis en sus Dionisiacas ${ }^{27}$ que las primeras nodrizas que cuidaron de Dionisos cuando fue

\footnotetext{
${ }^{25}$ Véase su Teogonía.

26 «T'ha enquimerat la gràcia fugitiva / d'un desig i ara ets deserta, oh ment. / Ai soledat sense el dolç pensament / i foll traüt sense paraula viva! // Però ¿què hi fa, si dins el teu oblit / la inquietud pregonament perdura? / Encara el goig sobre la carn s'atura, duent l'anunci d'algun cant no dit. // I ell és el foc sagrat que et perpetua / damunt les cendres del desolament; / no vulguis calma en ton oblit, oh ment, / oh folla que has gosat mirar-te nua» (Riba, 1988: 53).

${ }^{27}$ Son numerosas las referencias que aparecen sobre Dionisos y el fuego. En el Canto I: «Cuéntame, diosa, la historia de la asistencia del brillante lecho del Crónida, del jadeo del rayo que ejecutó el parto con centelleo nupcial, y del relámpago ayudante de la cámara de Sémele. Relátame el nacimiento de Baco, el dos veces nacido. Zeus lo extrajo, húmedo del fuego,
} 
arrebatado del incandescente vientre de Sémele ${ }^{28}$ fueron las llamas de la tormenta que Zeus mandó. Lo apolíneo y lo dionisíaco conviven fluctuando dentro del fuego desvelador de la existencia poética. El destino del poeta es el destino del fuego, tal y como concluye Riba al final de la elegía: «per a la nostra mel, que és filla de l'aire i la terra; / sí, però més del foc, dona, del foc sobre tot» (Riba, 2011: $55)$.

Riba relaciona a ese fuego revelador con las abejas y con su miel. El propio poeta escribe en su Presentació de les Elegies de Bierville:

[...] en tombar aquesta mena d'esperó que fa una de les roques, d'una guingueta que hi havia allí van volar unes abolles, símbol de poesia pels antics, i ens van voltar una estona el cap. Allò ens va fer pensar -i així acaba l'Elegia- en el nostre ofici, perquè la poesia és també, i al capdavall, un ofici, un ofici pel qual cal ser humil i coratjós (Medina, 1994: 132).

En efecto, las abejas siempre han tenido una significación relacionada con la poesía para los antiguos. Pero también han sido figuras que han formado parte del imaginario sagrado de Delfos. El propio Calímaco escribe: «A Deo no le llevan las abejas agua de cualquier procedencia, sino el pequeño chorro que mana, sin mancha y puro, de la fuente sacra: la suprema delicia» (Calímaco, 1980: 48).

Como también refleja Cirlot en su Diccionario de símbolos, una antigua tradición délfica atribuía a las abejas el haber construido el segundo templo erigido en Delfos. Georges Roux desvela la importancia mítica que las abejas han tenido siempre en este lugar sagrado de la Fócide y su fuente en el Himno homérico a Hermes ${ }^{29}$ :

En fin il y avait à Delphes même, au pied des Phédriades, trois énigmatiques divinités dont seuls nous parle l'auteur de l'hymne homérique à Hermès, trois nymphes-abeilles, avec l'aide desquelles Apollon aurait d'abord prophétisé. Le dieu déclare à son frère Hermès qu'il lui fait don de l'oracle par les abeilles: «i lest des abeilles, soeurs par la naissance, trois vierges fières de leurs ailes rapides. Leur tête est saupoudrée de Blanche farine[...] Ces nymphes-abeilles, dont Apollon fait cadeau à son jeune frère Hermès, ne donnent par leur vol de signe véridique au prophète que si elles «entrent en transes» après s'être gorgées de miel (Roux, 1976: 186).

El profesor Jaume Medina atiende acertadamente a la relación entre el simbolismo de estas abejas y el motivo central de las Horacianes de Miquel Costa i Llobera ${ }^{30}$. Pero basta con recordar a Riba y

\footnotetext{
como un embrión a medio formar; lo sacó del seno de su madre, no asistida por partera». Canto VI: «Pero, mientras el primer Dioniso era despedazado, el padre Zeus advirtió la trampa de la imagen del espejo de sombría imagen, y atacó con una antorcha vengadora a la madre de los Titanes». Canto VIII: «En efecto la novia de corta vida esperaba correr la misma suerte que Hera, esto es, ver en sus nupcias el encantador fulgor de un apacible rayo. [...] El brillante resplandor fue la partera, los rayos, nuestra Ilitía. En efecto, la llama celestial fue cuidadosa y liberó a Baco lanzándolo del seno carbonizado de la madre, cuando el himeneo tocaba a su fin por el matricida rayo» (de Panópolis, 1995: 55, 210, 258,260).

${ }^{28}$ Sémele fue abrasada por el fuego divino de Zeus.

29 «Hay unas venerables muchachas, hermanas de nacimiento, que se ufanan de sus raudas alas. Son tres y, con la cabeza cubierta de blanco polen, habitan su morada al pie de la garganta del Parnaso. Son maestras por su cuenta, de una adivinación a la que, aún de niño, me dedicaba con mis vacas. Mi padre no se preocupaba de ello. Desde allí luego, volando de una parte a otra, se nutren de los panales y dan cumplimiento a todas las cosas. Cuando, nutridas de rubia miel, entran en trance, consienten de buen grado en profetizar la verdad. Pero si se ven privadas de dulce manjar de los dioses mienten entonces agitándose unas a otras» (Bernabé, 1978: 173).

30 «[l'abella] símbol de la poesia (segons aclareix ell mateix); però les abolles bruzents, com els llorers de Salamina de l'elegia IX, tenen també el seu referente literari, un referente que es troba al poema l'abell de les Horacianes de Miquel
} 
su manera de existir en la literatura para ver que la tradición e influencias modelaban su propio existir como poeta. La miel de esas abejas son producto del fuego, tal y como apunta Riba en su último verso. Pero en diversos testimonios literarios se encuentra una clara relación entre la miel y la profecía. En la Olímpica VI (versos 43-47) Íamo, el adivino, es alimentado después de su nacimiento con miel ${ }^{31}$. Existe una predestinación a que Delfos sea el lugar del vaticinio y la poesía ${ }^{32}$. Boixareu expone que también la miel es lo resultante del sentimiento, convertido en fuego (Boixareu, 1978: 251). El aire y la tierra, los otros elementos que menciona Riba al final de la elegía pertenecen, como bien expone Boixareu, a la vida espiritual e instintiva, respectivamente. Todo ello construye al poeta. El propio Platón en el Íon escribe: «Los poetas, en efecto, nos dicen que ellos liban sus versos en fuentes de miel, en ciertos jardines y valles de las Musas, para traérnoslos a la manera en que lo hacen las abejas, y esos mismos revolotean a la manera de estas ¿no es verdad?»(Platón, 1993: 146).

El resultado del trabajo de las abejas, la miel, es el mismo resultado que se genera en el poeta tras fundirse en él el sentimiento y la experiencia interiores. Esta es una parte trascendente de la concepción ribiana del lirismo y en la que coincide con Valéry ${ }^{33}$. En realidad, Riba sabe - como buen poeta que es- que comprender que la poesía es la aceptación de un Apocalipsis originario del mito. Solo así puede sentir — convertida su escritura en quemadura- la desocultación de un acontecimiento de sí mismo, revelador. El fuego es un elemento análogo del sol, alcanzable pero peligroso si se toca. Es el sol alcanzado por el poeta. El mismo sol que ciega y que no puede mirarse fijamente a riesgo de perder la visión para siempre, como Tiresias. Solo a través de esta quemadura luminosa se alcanza el sentido Absoluto de la escritura poética. Cada poeta entrega su esencia al fuego — quizás como Dido se lanzó a la pira, por el mismo acto de amor- para transformarla en conocimiento.

\section{Bibliografía}

AMANDRY, P. (1975): Le mantique apollinienne a Delphes. Essai sur le fonctionement de l'Oracle. Nueva York, Arno.

Bernabé, A. (1978): Himnos homéricos. La Batracomioquia. Madrid, Gredos.

BoiXAReu, M. (1978): El jo poètic de Carles Riba i Paul Valéry. Barcelona, Edicions 62.

CALímACo (1980): Himnos, Epigramas y fragmentos. Trad. Luis Alberto de Cuenca y Prado y Máximo

Brioso Sánchez. Madrid, Gredos.

CIRLOT, J. E. (2011): Diccionario de símbolos. Madrid, Siruela.

Costa i Llobera (poeta admirat per Riba): «Sents tu l'abella brunzir? escolta-la com envers àtic modula màximes» (Medina, 1994: 292).

31 «Y de su seno enseguida, entre amables dolores, / Íamo vino a la luz. A él, afligida, / abandonó en el suelo. Pero dos serpientes de ojos brillantes, / por voluntad de los dioses, lo alimentaron cuidadosas / con inocuo veneno de abejas» (Píndaro, 1995: 97-98).

32 «Però també [el poema] ha de significar —i això és fonamental en el curs de les Elegies i ens pot explicar per què Riba va col·locar aquí aquest poema- el refús, basat en el cristianisme, de la idea d'una anticipació del futur. La palabra uates —d'on ve «vaticini», per exemple- serveix per a designar tant l'endeví com el poeta» (Miralles, 2007: 276).

33 «El lirismo es la voz del yo, lanzada en el tono más puro, si no el más alto. Pero esos poetas hablan de sí mismo como lo hacen los músicos, es decir, fundiendo las emociones de todos los acontecimientos precisos de sus vidas en una sustancia íntima de experiencia universal» (Valéry, 2010: 13). 
El camino délfico: transformación y plenitud del futuro en la escritura de las Elegies...

EliadE, M. (1986): Imágenes y símbolos. Trad. Carmen Castro. Madrid, Taurus.

- (1991): Mitos, sueños y misterios. Trad. Mariana de Alburquerque. Madrid, Grupo Libro 88. (2000): Tratado de Historia de las Religiones. Morfología y dialéctica de lo sagrado. Trad. A.

Madinaveitia. Madrid, Cristiandad.

EsQuilo (1986): Tragedias. Trad. B. Perea. Madrid, Gredos.

Flacelière, R. (1993): Adivinos y oráculos griegos. Trad. Néstor Míguez. Buenos Aires, Editorial Universitaria de Buenos Aires.

HERNÁNDEZ, D. (2008): Oráculos griegos. Madrid, Alianza.

HöldERlin, F. (1985): El Archipiélago. Trad. Luis Díez del Corral. Madrid, Alianza.

Medina, J. (1994): La plenitud poètica de Carles Riba. El període de les Elegies de Bierville.

Barcelona, Publicacions de l'Abadia de Montserrat.

Miralles, C. (2007): Sobre Riba. Barcelona, Proa.

Nerval, G. de (2004): Obra literaria: Poesía y prosa literaria. Trad. Tomás Segovia. Barcelona, Galaxia Gutenberg.

NiETzSCHE, F. (2004): El nacimiento de la tragedia. Trad. Andrés Sánchez Pascual. Madrid, Alianza.

PANÓPOLIS, N. (1995): Dionisiacas (Tomo I. Cantos I-XII). Trad. Sergio Daniel Manterola y Leandro Manuel Pinkler. Madrid, Gredos.

Pausanias (1994): Descripción de Grecia (VII-X). Trad. María Cruz Guerrero Ingelmo. Madrid, Gredos.

PínDARO (1995): Odas y Fragmentos. Madrid, Gredos.

Platón (1992): Crátilo (Diálogos II). Madrid, Gredos. (1993): Obras Completas. Madrid, Aguilar.

PlutARCo (2007): Sobre los oráculos. Palma de Mallorca, José J. de Olañeta.

REIS, J. (1997): Tratado de antropología de lo sagrado. Madrid, Trotta.

RIBA, C. (1984): Sobre poesía i sobre la meva poesía. Barcelona, Empúries.

(1988): Obres Completes I. Poesia. Barcelona, Edicions 62.

(1991): Cartes de Carles Riba II: 1939-1952. Barcelona, Institut d'Estudis Catalans.

(2011): Elegías de Bierville. Madrid, Libros del Aire.

Roux, G. (1976): Delphes, son oracle et ses dieux. Paris, Les belles Lettres.

SEFERIS, Y. (1999): Todo está lleno de dioses. México, Fondo de Cultura Económica.

Schajowicz, L. (1962): Mito y existencia. Preliminares a una teoría de las iniciativas espirituales. San Juan, Ediciones de la Torre-Universidad de Puerto Rico.

SCHWARZ, F. (2008): Mitos, ritos, símbolos. Antropología de lo sagrado. Buenos Aires, Biblos.

UnAmuno, M. de (1999): Antología poética. Madrid, Austral.

VAlÈry, P. (2010): De Poe a Mallarmé. Ensayos de poética y estética, Buenos Aires, El cuenco de plata. 